\begin{abstract}
The paper presents a two-country macroeconomic model in which the number of financial assets is endogenous. Imperfect substitutability of assets and international transaction costs give a comparative advantage to large markets, because of demand effects. Agents have more incentives to undertake risky investments on those markets; they can also diversify risk at a lower cost. Prices of financial assets are higher in the large area because asset markets are broader. We also analyse the impact of domestic transaction costs and issuing costs on financial markets and returns. Our theory has important implications for the pattern of international trade in risky assets.
\end{abstract}

This paper was produced as part of the Centre's Globalisation Programme

\title{
Financial Super-Markets:
}


Size Matters for Asset Trade

Philippe Martin and HJ IRe Rey

March 2000 
Series Editor: Graham Ingham

Published by

Centre for Economic Performance

London School of Economics and Political Science

Houghton Street

London WC2A 2AE

(C) Philippe Martin and HJ IPne Rey

submitted July 1999

ISBN 0753013657 
Individual copy price: $£ 5$ 


\section{Financial Super-Markets: \\ Size Matters for Asset Trade}

\section{Philippe Martin and HJ IRe Rey}

1. Introduction 1

2. The General Framework 2

3. Equilibrium Demand and Supply on Asset Markets 5

4. Prices, Financial Market Development and Risk Diversification 8

5. Characteristics of the Equilibrium 10

6. Perfect Competition on Asset Markets 12

$\begin{array}{ll}\text { 7. Welfare Implications } & 13\end{array}$

8. Domestic Transaction Costs and Issuing Costs 14

9. Conclusion

$\begin{array}{ll}\text { References } & 17\end{array}$

The Centre for Economic Performance is financed by the Economic and Social Research Council. 


\section{Acknowledgements}

We thank Richard Baldwin, Benoit Coeuré, Pierre-Philippe Combes, Hans Genberg, Pierre-Yves Geoffard, Olivier Jeanne, Nobuhiro Kiyotaki, Erzo Luttmer, Andres Neumeyer, Victor Norman, Gianmarco Ottaviano, Richard Portes, Diego Puga and Jacques Thisse for helpful comments as well as participants at seminars at NYU, IMF, Berkeley, Insead, Bergen, Geneva, Frankfurt, LSE. The second author acknowledges gratefully the warm hospitality of the Institute for International Economic Studies (Stockholm). We thank especially Marco Pagano and Ken Rogoff for detailed comments. We are also grateful to the Fondation Banque de France for financial assistance.

Philippe Martin is at CERAS-ENPC, Paris, GIIS, Geneva and CEPR, and HJ IPhe Rey is at the London School of Economics and Political Science and CEPR. 


\section{Financial Super-Markets: Size Matters for Asset Trade}

\section{Philippe Martin and HJ IRe Rey}

\section{Introduction}

The US is sometimes described as a "super-market" for financial assets. American markets offer a wide range of financial assets, they are both very broad and liquid. International capital flows in and out of the US are very large and, in general, the pattern of trade in risky assets world-wide is heavily concentrated in a few big markets. Surprisingly, trade in risky assets has received little attention in the literature, relative to trade in goods.

The paper offers a theory linking the size of economies with asset returns, the extent of portfolio diversification and the pattern of trade in risky assets. We analyse a two-country macroeconomic world where the set of traded financial assets is endogenous and determined in equilibrium by the agents' choices of risky projects to develop in each economy. This environment has three key characteristics: (i) assets are imperfect substitutes, (ii) the investment technology presents some indivisibility, (iii) cross-border asset trade entails some transaction costs. In this world, size matters. Financial markets are broader and asset prices are higher in the large economy. This is because aggregate demand for the assets of the large economy is higher. This comes from the existence of transaction costs that generate a home bias.

In accordance with our results, some recent empirical papers have pointed towards significant effects of market size and financial market integration on the cost of capital ${ }^{1}$. These papers typically find that companies that are listed on a non-US stock market and then become listed on the New York Stock Exchange experience an increase in their share price. Usually, the greater the market segmentation, the greater the increase in the share price ${ }^{2}$. Merton's (1987) model of investor recognition or the Amihud and Mendelson (1986) liquidity model ${ }^{3}$ may give some rationale for these findings. But they fall short of providing a unifying framework where international trade in assets, transaction costs and financial markets development can be discussed. We develop such a framework.

In our model, the decision by one agent to develop a new risky investment and to put a new security on the market enhances risk-sharing opportunities for all agents in the world. A large financial area supplies more assets and has a larger capitalisation, because in equilibrium the price of assets is higher, due to a larger demand. Its financial markets will therefore be more developed and risk diversification will be less costly. The model also puts forward the importance of size of economies and transaction costs for gross trade flows in assets. This is consistent with recent empirical evidence on bilateral gross cross-border equity flows described in Portes and Rey (2000). Our approach is related to the financial and macroeconomic literature on incomplete asset markets and risk-sharing as well as to the

See for example Bekaert and Harvey (1997), Foerster and Karolyi (1998), Miller (1999).

See Alexander, Cheol and Janakiraman (1988) or Miller (1999).

See also Pagano (1988), (1989). 
literature on trade under uncertainty. Allen and Gale (1994) provide an excellent account of the literature on financial innovation and risk sharing. ${ }^{4}$ But in their work the number of risky projects is exogenously given (unlike here). Issuing costs lead to market incompleteness; they do not introduce transaction costs, nor analyse international asset trade. More closely related to this paper is Pagano (1993). He looks at the decision of flotation of companies on the stock market and introduces trading externalities. However, his model is a pure exchange closed economy while we endogenise the investment decisions of entrepreneurs and analyse international capital flows.

Our modelling approach is linked to Acemoglu and Zilibotti (1997), which builds on a market structure (endogenous number of Arrow-Debreu projects) similar to ours. A major difference, besides the fact that their world has no transaction costs, is that we adopt a monopolistically competitive environment - coming naturally from the imperfect substitutability of financial assets - as opposed to their competitive framework. They focus exclusively on capital accumulation and growth; we study the interactions between size, incompleteness of markets, and price of financial assets in open economies.

The literature on trade and uncertainty has been pioneered by Helpman and Razin (1978). They introduced a stock market economy à la Diamond into a framework that fits the standard Ricardian and Hecksher-Ohlin models of international trade. More recent contributions have extended this line of work, including Svensson (1988), and Persson and Svensson (1989). Some of the issues raised by these authors are similar to ours but the approach adopted is very different. In their papers the number of securities traded is exogenous and the analysis of asset trade is based on autarky prices.

Finally, our analysis of trade in assets has some common characteristics with the analysis of trade in goods with monopolistic competition that was introduced by Krugman (1979) and Dixit and Norman (1980).

The general framework is presented in Section 2. Section 3 derives the equilibrium demands and supplies on asset markets. Sections 4 and 5 analyse the impact of country size on asset prices, financial market development, risk diversification and the current account. The case of perfect competition is briefly discussed in Section 6. Welfare implications of the model are derived in Section 7 and the impact of domestic transaction costs and issuing costs is presented in Section 8. Section 9 concludes.

\section{The General Framework}

We consider a two-period model with two countries or financial areas, A and B, large and small. They are respectively populated with $\mathrm{n}_{\mathrm{A}}$ and $\mathrm{n}_{\mathrm{B}}$ risk-averse immobile identical agents with $\mathrm{n}_{\mathrm{A}}>\mathrm{n}_{\mathrm{B}}$. In the first period all agents in the world are endowed with y units of a freely traded good (the numéraire), which they can choose to consume or invest in fixed size risky projects. In the second period, there are $\mathrm{N}$ exogenously determined and equally likely states of nature and $\mathrm{M}$ different contingent projects whose payoffs are the following:

$$
\text { project } i \text { pays }=\left\{\begin{array}{l}
\mathrm{d} \text { if state } \mathrm{i} \in\{1, \ldots, \mathrm{N}\} \text { occurs } \\
0 \text { otherwise }
\end{array}\right.
$$

See also Magill and Quinzii (1996) who survey the general equilibrium theory of incomplete markets and Obstfeld and Rogoff (1996). 
Shares of these projects (claims on the risky dividends) are traded on the stock markets of the two countries 5 . This implies that investing in a specific project (either directly or through the stock market) is equivalent to buying an Arrow-Debreu asset that pays only in one state of nature. This formalisation is close to the one of Acemoglu and Zillibotti (1997). It captures the first main feature of our model: different projects and assets are imperfectly correlated so that assets are imperfect substitutes and variety improves safety.

The fixed size investment projects are costly to develop. An agent $h_{A} \in\left\{1, \ldots n_{A}\right\}$ chooses to develop $\mathrm{z}_{\mathrm{hA}}$ different projects $\left(\mathrm{z}_{\mathrm{hB}}\right.$ for an agent $\mathrm{h}_{\mathrm{B}} \in\left\{1, \ldots \mathrm{n}_{\mathrm{B}}\right\}$ in the small country). $\mathrm{M}$, the total number of projects (and assets) in the world is $\sum_{h_{A}=1}^{n_{A}} z_{h A}+\sum_{h_{B}=1}^{n_{B}} z_{h B}$ since, in equilibrium, agents will have no interest in duplicating a project that has already been developed and all agents of the same country will develop the same number of projects. The set of projects that have been developed in country $A$ and $B$ are $M_{A}$ and $M_{B}$ respectively. The equilibrium total number of assets in the world $M=M_{A}+M_{B}$ is endogenous. We restrict parameters so that $\mathrm{M}<\mathrm{N}$ : markets in general will not be complete, meaning that it will not be possible to eliminate all risk by holding a portfolio of all traded assets. In some states of the world, there will be no production. Hence, in general, the matrix of the pay-offs will have the following form:

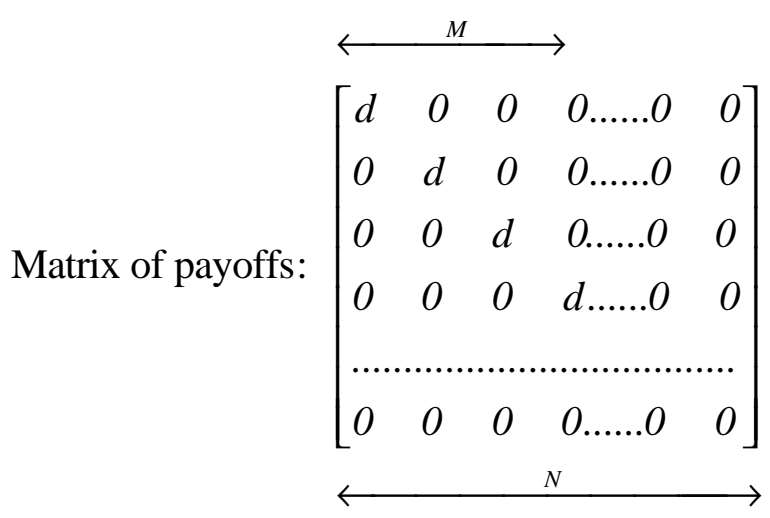

The cost of each new project is increasing with the number of projects an agent is performing: we assume that the monitoring of each project becomes more complex and costly as the number of projects increases. The total cost in units of the numéraire of the investment in risky projects of an agent $h_{A}$ is $f\left(z_{h A}\right)$, with $f^{\prime}(z)>0$ and $f^{\prime \prime}(z)>0$. The investment cost function in country $B$ is similar. There is no restriction on the development of new projects. This will determine the equilibrium number of projects and therefore the equilibrium number of assets. One way to interpret the model is that the risky projects that agents develop are combined to create firms so that each agent creates a firm with possibly a different number of projects.

\section{Transaction costs}

In the first period, agents raise capital by selling shares of their projects and they buy shares of other projects. The second essential feature of the model is the presence of international transaction costs on asset markets. When agents trade assets, they incur a transaction cost $\tau$, which is paid in units of the share itself. The same transaction cost also applies on the

We assume the existence of a costless monitoring mechanism which ensures agents do not default in period 1 . 
stochastic dividend and is paid in units of the dividend ${ }^{6}$. Note that similarly to a recent strand of trade and economic geography literature the transaction cost is modelled as an iceberg cost: part of the share and part of the dividend "melt" during the transit. The iceberg form greatly simplifies the results because it eliminates the need to introduce financial intermediaries as an additional sector ${ }^{7}$. It also implies that the elasticity of demand for an asset with respect to its price is the same whether the transaction cost is paid or not, that is whether the asset is a domestic or a foreign one.

The presence of international transaction $\operatorname{costs}^{8}$ on the trade in assets captures different types of costs: (1) banking commissions and variable fees; (2) exchange rate transaction costs; (3) some information costs.

There are two ways to introduce these transaction costs on the international trade in assets. The first is to make buyers of the assets bear the transaction cost. In this case, the amount paid by an agent $h_{B}$ located in country $B$ to buy an asset sold on the stock market in country $\mathrm{A}$ by an agent $\mathrm{h}_{\mathrm{A}}$ is: $p_{h_{A}} s_{h_{B}}^{h_{A}}(1+\tau)$ where $p_{h_{A}}$ is the price of a share of a project developed by agent $\mathrm{h}_{\mathrm{A}}$ and $s_{h_{B}}^{h_{A}}$ is agent $\mathrm{h}_{\mathrm{B}}$ demand for an asset sold by agent $\mathrm{h}_{\mathrm{A}}$. In the rest of the paper superscripts will identify the seller and subscripts the buyer. If an asset pays a dividend $d$ in period two then a shareholder in country $B$ will receive only $(1-\tau) d$ per share. Profits generated by projects in country A are denominated in currency of country A so that agents in country B have to incur the transaction cost at that stage too'.

The second possible way to introduce transaction costs is to have project owners bear the transaction cost. These two ways of introducing transaction costs produce the same results as long as we assume that international transaction costs paid by agents buying shares and by project owners selling shares are identical ${ }^{10}$.

\section{Budget constraint}

We choose to present the model so that buyers pay the transaction costs as they anyway bear the cost. In this configuration, the budget constraint for an agent $h_{A}$ in country $A$ is:

$$
c_{1 h_{A}}+f\left(z_{h_{A}}\right)+\sum_{i \notin z_{h A}}^{M_{A}} p_{i} s_{h_{A}}^{i}+\sum_{j}^{M_{B}}(1+\tau) p_{j} s_{h_{A}}^{j}=y+\sum_{k}^{z_{h_{A}}} p_{h_{A}}^{k} \alpha_{h_{A}}^{k}
$$

where $\mathrm{c}_{\mathrm{hA}}$ is consumption of agent $\mathrm{h}_{\mathrm{A}}$ in period 1 . The second term on the left-hand side is the cost of investment in risky projects. The two last terms on the left-hand side represent the demands for domestic and foreign assets. There are $\left(\mathrm{M}_{\mathrm{A}^{-}} \mathrm{Z}_{\mathrm{hA}}\right)$ different domestic assets that agent $h_{A}$ will demand as he will only buy assets of projects he has not developed himself. There are $\mathrm{M}_{\mathrm{B}}$ different foreign assets on which he will have to incur the transaction cost $\tau$. On the revenue side, in addition to endowment $\mathrm{y}$, agent $\mathrm{h}_{\mathrm{A}}$ will sell a portion $\alpha_{h_{A}}^{k}$ of each project $\mathrm{k} \in \mathrm{Z}_{\mathrm{hA}}$ that he has developed. The budget constraint of an agent $\mathrm{h}_{\mathrm{B}}$ in country $\mathrm{B}$ is symmetric:

\footnotetext{
For our set up to make sense, we need to assume that these transaction costs cannot be evaded by going through the goods market on which, for convenience, we assume no transaction costs.

See Bisin (1998) for a model with costly financial intermediation and endogenous incomplete markets.

We introduce transaction costs on domestic financial transaction too in Section 8 of the paper.

The transaction cost could be eliminated either on the purchase of assets or on the dividends (but not both of course) without changing any of our qualitative results.

10 Agents acting as portfolio investors and as project owners are indifferent between the two systems

because ransaction costs will be passed on entirely through a higher price to agents buying shares.
} 


$$
c_{1 h_{B}}+f\left(z_{h_{B}}\right)+\sum_{i \notin z_{h B}}^{M_{B}} p^{i} s_{h_{B}}^{i}+\sum_{j}^{M_{A}}(1+\tau) p^{j} s_{h_{B}}^{j}=y+\sum_{k}^{z_{h_{A}}} p_{h_{A}}^{k} \alpha_{h_{A}}^{k}
$$

\section{Utility}

The utility of an agent $\mathrm{h}_{\mathrm{A}}$ in country A has the following form:

$$
U_{h_{A}}=c_{1 h_{A}}+\beta E\left(\frac{c_{2 h_{A}}^{1-1 / \sigma}}{1-1 / \sigma}\right)
$$

where $\beta$ is the rate of discount of the future. The utility of agents in country B is similar. $\sigma$ is the inverse of the degree of risk aversion and is also the elasticity of substitution between assets. The linearity of the utility function in the first period enables us to derive simple closed form analytical solutions, while keeping all the insights of the model ${ }^{11}$. The state of the world is revealed at the beginning of the second period. Hence, given the description of the payoffs of the different projects, the expected utility of agent $\mathrm{h}_{\mathrm{A}}$ is:

$$
\begin{aligned}
E U_{h_{A}} & =c_{1 h_{A}}+\beta \frac{1}{N} \frac{d^{1-1 / \sigma}}{1-1 / \sigma}\left(\sum_{i \notin z_{h A}}^{M_{A}} s_{h_{A}}^{1-1 / \sigma}\right)+\beta \frac{1}{N} \frac{[d(1-\tau)]^{1-1 / \sigma}}{1-1 / \sigma}\left(\sum_{j}^{M_{B}} s_{h_{A}}^{j^{1-1 / \sigma}}\right) \\
+ & \beta \frac{1}{N} \frac{d^{1-1 / \sigma}}{1-1 / \sigma}\left(\sum_{k}^{z_{h_{A}}}\left(1-\alpha_{h_{A}}^{k}\right)^{1-1 / \sigma}\right)
\end{aligned}
$$

The second element in equation (3) is the expected consumption in states $i$ that are backed by assets of risky projects developed by agents in country A other than those developed by agent $\mathrm{h}_{\mathrm{A}}$ himself. The third element is the expected consumption in states $\mathrm{j}$ backed by assets of risky projects developed by agents in country B. The last element is the expected consumption in states which are backed by assets of risky projects developed by the agent $h_{A}$ himself. The measure of the extent to which he has decided not to diversify his own risk is therefore: $1-\alpha_{h_{A}}^{k}$ for each project/asset $\mathrm{k} \in\left\{1, \ldots, \mathrm{Z}_{\mathrm{hA}}\right\}$. The expected utility of an agent in country $\mathrm{B}$ is symmetric.

\section{Equilibrium Demand and Supply on Asset Markets}

Agents maximise utility under their budget constraint. Agent $\mathrm{z}_{\mathrm{hA}}$ in country A chooses consumption in period $1, \mathrm{c}_{1 \mathrm{hA}}$, the number of projects $\mathrm{Z}_{\mathrm{hA}}$ he will develop, the demands for the different assets (domestic and foreign) and the portion of each of his projects that he will retain in the second period: $1-\alpha_{h_{A}}^{k}$ for each project/asset $\mathrm{k} \in\left\{1, \ldots, \mathrm{z}_{\mathrm{hA}}\right\}$. When buying shares on the stock market, agents are price takers. Note also that agents when making these choices do not internalise the impact they have on other agents' welfare. In particular, they do not internalise

11 We discuss the CES case further at the end of Section 4. 
the impact that the choice of the number of projects per agent has on the possibility for other agents to diversify risk ${ }^{12}$. The fixed cost that is required to develop a new project also insures that no agent will ever find it optimal to replicate an already existing project. The reason is that if he were to do so, the supply of the corresponding asset would necessarily increase so that its equilibrium price would decrease. It will therefore be more profitable to develop a project that has not been opened yet ${ }^{13}$.

\section{Market structure}

Each agent has a potential monopoly power on the projects that he has developed and therefore on the sale of the assets that correspond to these projects. This is a departure from the ArrowDebreu world where asset markets are assumed to be perfectly competitive. It is easy to check that the perceived elasticity of demand for any asset $\mathrm{k}$ with respect to its price is: ( $\partial \alpha^{\mathrm{k}} /$ $\left.\partial \mathrm{p}^{\mathrm{k}}\right) /\left(\alpha^{\mathrm{k}} / \mathrm{p}^{\mathrm{k}}\right)=-\sigma, \mathrm{k} \in \mathrm{M}$. The owner of the asset will exploit this imperfectly competitive structure and will sell only a portion of his project ${ }^{14}$. This means that in equilibrium the developer of the project will remain the largest shareholder of the project. This structure of the market also implies that $\sigma$, the price elasticity, is necessarily more than one. Otherwise the model would be degenerate as asset suppliers would always be better off selling less of the asset at a higher price.

Because all agents in the same country are identical and the projects are symmetric, the demands for assets of a given country by agents of the same nationality will be symmetric. Even though agents, in equilibrium, will not be identical because they will hold different amounts of the different assets, they will be symmetric in the sense that their diversification choice will be identical. Also, the price of all projects/assets developed by agents of the same country will be identical for the same reason. Hence, from now on we will in general omit notations that refer to the identity of the agents and of the assets. Agents (and their projects/assets) will only be identified by their nationality A or B. As for the demands for assets, the superscript denotes the origin of the asset and the subscript denotes the nationality of the buyer. Hence, for example, $s_{A}^{B}$ is the demand for an asset of country B by an agent of country A.

The first order conditions are such that we find the different demands for shares as a function of $\alpha_{\mathrm{A}}$ and $\alpha_{\mathrm{B}}$ which represent the extent of diversification in each of the two countries.

$$
\begin{aligned}
& s_{A}^{A}=\left(1-\alpha_{A}\right)\left(\frac{\sigma-1}{\sigma}\right)^{\sigma} ; s_{A}^{B}=\left(1-\alpha_{A}\right)\left(\frac{\sigma-1}{\sigma}\right)^{\sigma} \frac{(1-\tau)^{\sigma-1}}{(1+\tau)^{\sigma}}\left(\frac{p_{A}}{p_{B}}\right)^{\sigma} \\
& s_{B}^{B}=\left(1-\alpha_{B}\right)\left(\frac{\sigma-1}{\sigma}\right)^{\sigma} ; s_{B}^{A}=\left(1-\alpha_{B}\right)\left(\frac{\sigma-1}{\sigma}\right)^{\sigma} \frac{(1-\tau)^{\sigma-1}}{(1+\tau)^{\sigma}}\left(\frac{p_{B}}{p_{A}}\right)^{\sigma} \\
& s_{A}^{A}=p_{A}^{-\sigma}\left(\frac{\beta}{N} d^{1-1 / \sigma}\right)^{\sigma} ; s_{B}^{B}=p_{B}{ }^{-\sigma}\left(\frac{\beta}{N} d^{1-1 / \sigma}\right)^{\sigma}
\end{aligned}
$$

\footnotetext{
This is similar to Pagano (1993).

We assume that the choice of projects by all agents is public knowledge.

The fact that firms extensively buy and sell their own stocks to affect the price of their shares suggests that this structure is quite realistic. However we show in Section 6 that the monopolistic competition structure on asset markets is not essential for most of our results.
} 
Result 1: Agents in both countries do not fully diversify their domestic portfolio: $1-\alpha_{\mathrm{A}}>$ $s_{A}^{A}$ and $1-\alpha_{B}>s_{B}^{B}$.

Because all assets are symmetric, full domestic diversification would imply in particular that agents keep no more ownership of their own projects than they buy of projects developed by other agents in the same country ${ }^{15}$. If agents fully diversified in country A, they would set: $1-\alpha_{A}=s_{A}^{A}$. From equation (4), it is easy to check that this is not the case $(\sigma>1)$ and that agents in both countries keep more shares of their own project than they buy of those developed by agents in the same country. By doing so, each agent exploits the non-competitive structure of the asset market ${ }^{16}$. This also implies that if we interpret firms in our framework to be projects combinations, then firms have, in equilibrium, a "nationality". There is an agent with a specific nationality who chooses optimally to keep a higher share of the project he has himself developed.

The last line of equation (4) just says that the demand for assets are decreasing in the price and increasing in the dividend $\mathrm{d}$. We use the equilibrium conditions for each stock market and for each asset; that implies that the amount of shares offered for a specific asset equals the aggregate domestic demand plus the aggregate foreign demand inclusive of transaction costs:

$$
\begin{aligned}
& \text { stock market in } A: \alpha_{A}=\left(n_{A}-1\right) s_{A}^{A}+(1+\tau) n_{B} s_{B}^{A} \\
& \text { stock market in } B: \alpha_{B}=\left(n_{B}-1\right) s_{B}^{B}+(1+\tau) n_{B} s_{A}^{B}
\end{aligned}
$$

In this case, we learn that the portions of each project sold on the stock markets, are respectively:

$$
\alpha_{A}=\frac{n_{A}-1+n_{B} \phi}{n_{A}-1+n_{B} \phi+\left(\frac{\sigma}{\sigma-1}\right)^{\sigma}} ; \alpha_{B}=\frac{n_{B}-1+n_{A} \phi}{n_{B}-1+n_{A} \phi+\left(\frac{\sigma}{\sigma-1}\right)^{\sigma}}
$$

where $\phi=\left(\frac{1-\tau}{1+\tau}\right)^{\sigma-1}$ is a useful transformation of transaction costs and is less than 1 . When $\phi$ increases, transaction costs are lower.

Result 2: There is more diversification in the large country than in the small one: $\alpha_{A}>\alpha_{B}$. Project owners in the large country choose to retain fewer shares of their projects and to sell more on the stock market. In this sense the financial markets are more developed in the large country so there is a market size effect on financial markets.

\section{Prices, Financial Market Development and Risk Diversification}

Using the first order conditions and the market equilibrium, we obtain the prices for shares on the different markets:

\footnotetext{
15 We show below that the model also features a home bias in portfolio choice.

16 For the monopolistic competition structure to make sense the parameters must be such that the number of projects each agent develops is small relative to the total number of projects. Otherwise, agents would take into account the effect of their pricing policy on the aggregate outcome.
} 


$$
\begin{aligned}
& p_{A}=\frac{\beta}{N} d^{1-1 / \sigma}\left[n_{A}-1+n_{B} \phi+\left(\frac{\sigma}{\sigma-1}\right)^{\sigma}\right]^{1 / \sigma} \\
& p_{B}=\frac{\beta}{N} d^{1-1 / \sigma}\left[n_{B}-1+n_{A} \phi+\left(\frac{\sigma}{\sigma-1}\right)^{\sigma}\right]^{1 / \sigma}
\end{aligned}
$$

Result 3: The price for shares of projects developed by agents located in the large country is higher than those developed in the small country: $\mathrm{p}_{\mathrm{A}}>\mathrm{p}_{\mathrm{B}}{ }^{17}$

Also, the price ratio of the large country assets to the small country assets is increasing in the level of the international transaction costs. If international transaction costs were zero $(\phi$ $=1$ ), then asset prices would be equal in the two countries. Note also that if agents were risk neutral, which in our set up means that assets are perfect substitutes $(\sigma \rightarrow \infty)$, then again the price difference between the two countries vanishes. Result 3 has an immediate implication on the expected returns of an asset which is just: $d /\left(\mathrm{Np}_{\mathrm{i}}\right), \mathrm{i}=\mathrm{A}, \mathrm{B}$. Hence, the expected return on assets of the large country is smaller than in the small country.

Next, we determine the optimal choice for $\mathrm{z}_{\mathrm{A}}$ and $\mathrm{z}_{\mathrm{B}}$ the number of projects developed by each agent in country $\mathrm{A}$ and $\mathrm{B}^{18}$ :

$$
f^{\prime}\left(z_{A}\right)=p_{A} ; f^{\prime}\left(z_{B}\right)=p_{B}
$$

Because there is perfect competition on the market for developing projects, the choice for the number of projects, $z_{A}$ and $z_{B}$, is such that the price of the asset $\left(p_{A}\right.$ and $p_{B}$ respectively) is equal to the marginal cost of the last project. As long as the cost function $\mathrm{f}$ is convex, the large country which also has the high asset price will have more projects per agent.

Result 4: The number of projects per agent developed in the large country is higher than in the small country: $\mathrm{z}_{\mathrm{A}}>\mathrm{z}_{\mathrm{B}}$. We can interpret this result as saying that firms in the large country are made of more projects; or are of larger size.

Depending on the exact form of the cost function for developing new projects, the number of assets may be lower than or equal to the number of states of the world, so that markets may be complete or incomplete. We will only consider the more realistic case where financial markets are incomplete: not all states of the world will be covered by an ArrowDebreu asset. In some states of the world consumption will be zero in the second period.

To gain intuition on these results, we come back to the first order conditions of the agents in the large country. When choosing how much to sell of their own projects on the domestic stock market, agents set the marginal cost of doing this equal to the marginal gain (the Lagrangian is equal to 1 because of linearity of utility in first period) so that:

$$
\frac{\beta}{N} d^{1-1 / \sigma}\left(1-\alpha_{A}\right)^{-1 / \sigma}=p_{A}\left(\frac{\sigma-1}{\sigma}\right) ; \frac{\beta}{N} d^{1-1 / \sigma}\left(1-\alpha_{B}\right)^{-1 / \sigma}=p_{B}\left(\frac{\sigma-1}{\sigma}\right)
$$

\footnotetext{
17 Pagano (1993) has multiple equilibria because in his model the price of assets is increasing in the number of assets, unlike here.

18 Because the number of projects must be a natural number we have to assume that $\mathrm{N}$ is large enough so that the equilibrium just described can be considered as an approximation.
} 
These are respectively the optimality condition for the representative agent in A and in B. The expected marginal cost of selling one more share of the project developed by the agent is the expected welfare loss due to consumption thus foregone (left-hand side of the equation). Note that because of the concavity of expected utility in consumption, this marginal cost is naturally rising with the portion of the project sold. The marginal gain is less than the price of the asset as an increase in the supply of the asset implies a decrease in its price. At the optimum, the price of a share is equal to its marginal cost multiplied by the mark up $\sigma /(\sigma-1)$. The market size effect comes on the demand side $^{19}$. Using the equilibrium on asset markets, and the demands given in (4), we get:

$$
\alpha_{A}=\left(\frac{\beta d^{1-1 / \sigma}}{N}\right)^{\sigma} p_{A}^{-\sigma}\left(n_{A}-1+n_{B} \phi\right) ; \alpha_{B}=\left(\frac{\beta d^{1-1 / \sigma}}{N}\right)^{\sigma} p_{B}^{-\sigma}\left(n_{B}-1+n_{A} \phi\right)
$$

Because there are more agents in country A, and because of the existence of transaction costs $(\phi<1)$, the total demand for an asset of the large country will be larger than the demand for an asset in the small country for a given price. As can also be seen from the equation above, demands in both countries are decreasing in the price.

With Graph 1, we illustrate the determination of the prices of assets, $\mathrm{p}_{\mathrm{A}}$ and $\mathrm{p}_{\mathrm{B}}$, and of the extent of diversification, $\alpha_{\mathrm{A}}$, and $\alpha_{\mathrm{B}}$ which are also measures of the supply of assets:

19 This market size effect is reminiscent of the home market effect in the new trade and new geography literatures. 


\section{Graph 1: determination of asset price and diversification}

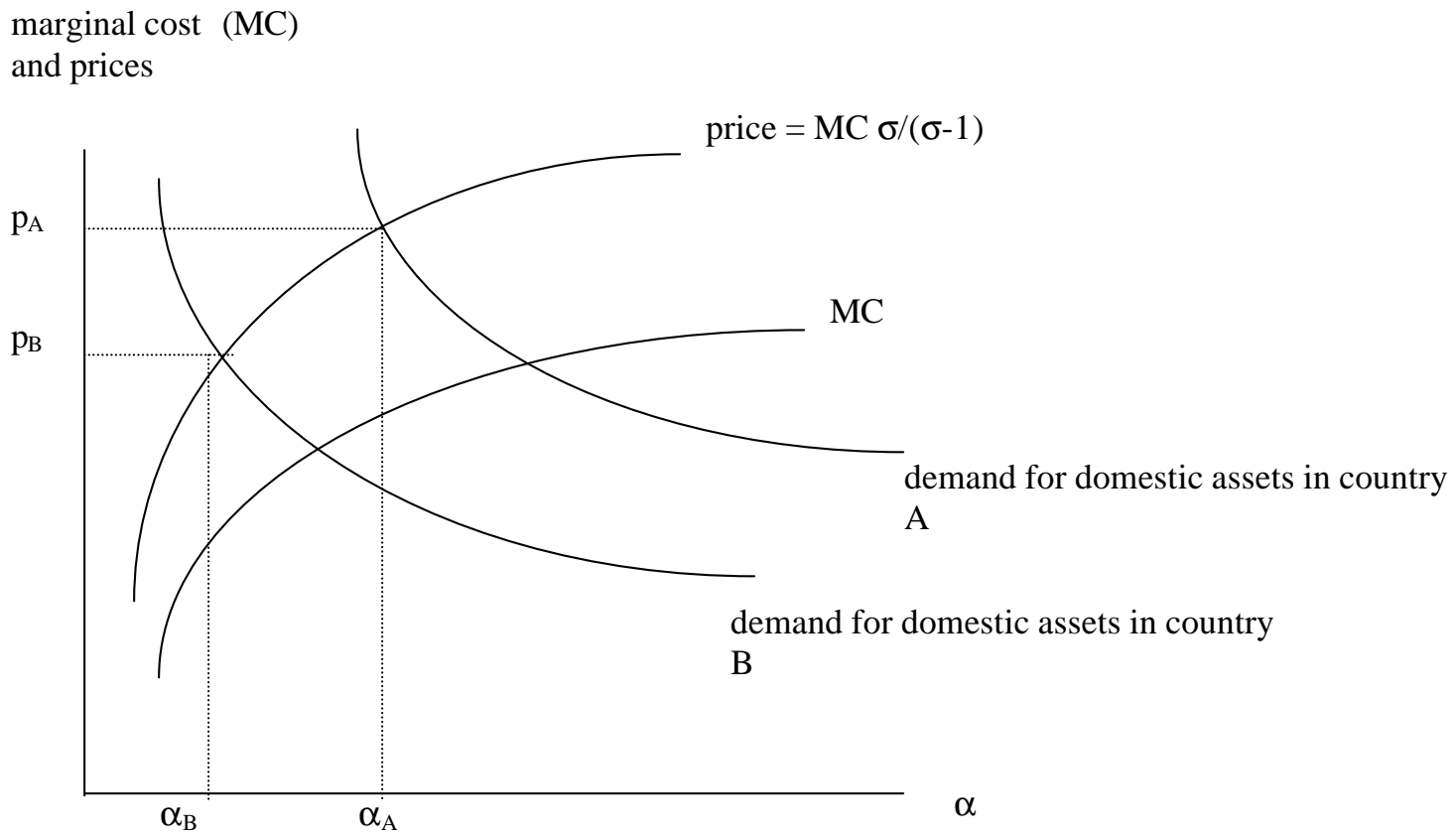

Note that in this paper we have abstracted from wealth effects by using a linear utility in the first period. If we had a CES function in the first period, we could show analytically that a country with a higher per capita endowment y will also have in autarky a higher demand for assets and higher asset prices. The intuition for wealth effects is similar to the one illustrated in the above graph for size effects.

\section{Characteristics of the Equilibrium}

\section{Capitalisation}

The market size effect also shows up in the market capitalisation of the two countries. In our model, this is the market value of shares traded on the stock market. Calling $C_{A}$ and $C_{B}$, the market capitalisations per capita as a share of income in the two countries, then:

$$
C_{A}=\frac{z_{A} p_{A} \alpha_{A}}{y} ; C_{B}=\frac{z_{B} p_{B} \alpha_{B}}{y}
$$

Result 5: Market capitalisation per capita in percentage of income is larger in the large country than in the small one: $\mathrm{C}_{\mathrm{A}}>\mathrm{C}_{\mathrm{B}}$.

From that point of view, the financial markets of the large country are more developed than those of the small country; there are more assets traded on these markets both in absolute terms and relative to income $\left(\mathrm{z}_{\mathrm{A}}>\mathrm{z}_{\mathrm{B}}\right)$. Financial markets are also more developed because project owners choose to sell more of their shares on the stock market $\left(\alpha_{A}>\alpha_{B}\right)$. Finally the value of these shares is higher $\left(\mathrm{p}_{\mathrm{A}}>\mathrm{p}_{\mathrm{B}}\right)$. 


\section{Variance of stock indices}

We can also derive the variance of returns on each market. Suppose that one dollar is invested equally in each asset of a country. This is the closest measure of stock market indices in our model. The variance of the return of this stock market index is then:

$$
\operatorname{var} I_{A}=\frac{d^{2}}{N^{3} p_{A}^{2} n_{A} z_{A}}\left(N-n_{A} z_{A}\right)^{2} \quad ; \quad \operatorname{var} I_{B}=\frac{d^{2}}{N^{3} p_{B}^{2} n_{B} z_{B}}\left(N-n_{B} z_{B}\right)^{2}
$$

Result 6: The variance of the return of the stock index of the large country is smaller.

The intuition is simply that the stock market of the large country offers more diversification and therefore less risk because the number of assets on the large market is higher.

\section{Home bias}

Finally, we want to analyse whether the equilibrium features a "home bias" in the portfolio choice. There are several ways to define a home bias in the context of our model. Here, we derive the share of domestic assets in the portfolio and compare it to the share of the economy in the world. The value of the non-traded portion of wealth (the part of each project kept by the project owner) is given by the indirect utility function which at the optimum is valued at the market price. Computing this ratio, we get that a home bias exists in country A and in country B if:

$$
\begin{gathered}
\frac{n_{A}-1+\left(\frac{\sigma}{\sigma-1}\right)^{\sigma}}{n_{A}-1+n_{B} \phi+\left(\frac{\sigma}{\sigma-1}\right)^{\sigma}}>\frac{n_{A}}{n_{A}+n_{B}} \\
\frac{n_{B}-1+\left(\frac{\sigma}{\sigma-1}\right)^{\sigma}}{n_{B}-1+n_{A} \phi+\left(\frac{\sigma}{\sigma-1}\right)^{\sigma}}>\frac{n_{B}}{n_{A}+n_{B}}
\end{gathered}
$$

It is easy to check that indeed this is the case in both countries as long as international transaction costs exist $(\phi<1)$ or that the asset market is imperfectly competitive ( $\sigma$ is finite).

\section{Current account}

The current account of the large country is simply aggregate output minus consumption and investment:

$$
\begin{aligned}
& C A_{A}=n_{A}\left[y-c_{1 A}-f\left(z_{A}\right)\right]= \\
& \frac{\beta}{N} d^{1-1 / \sigma} n_{A} n_{B} \phi\left\{z_{B}\left[n_{B}-1+n_{A} \phi+\left(\frac{\sigma}{\sigma-1}\right)^{\sigma}\right]^{1 / \sigma-1}-z_{A}\left[n_{A}-1+n_{B} \phi+\left(\frac{\sigma}{\sigma-1}\right)^{\sigma}\right]^{1 / \sigma-1}\right.
\end{aligned}
$$

The current account in country B is just the opposite. The sign of the current account of the large country is ambiguous. It is easy to show that it is negative if: 


$$
p_{A}^{1-\sigma} z_{A}>p_{B}^{1-\sigma} z_{B}
$$

which will be the case if parameters are such that:

$$
f^{\prime}(z)>(\sigma-1) z f^{\prime \prime}(z) \text { or } \quad \frac{\partial z}{\partial p} \frac{p}{z}>\sigma-1
$$

Hence, the large country runs a current account deficit if the price elasticity of investment projects is large relative to the elasticity of substitution between assets. The intuition is that in this case, the large country offers many more assets than the small country as the high price of assets in the large country induces agents to invest more in risky projects. This will be the case if the cost function is not too convex. Moreover, when the elasticity of substitution between assets is low (the relative risk aversion is high) agents of the small country will accept to bear the high price of the large country assets so as to diversify risk. In this case, the total value of assets bought by the small country from the large country will be high and the large country will run a current account deficit, selling more assets than it buys.

The model generates bilateral gross trade flows in assets, which are positively correlated with the size of the economies and negatively correlated with transaction costs. Recent empirical evidence described in Portes and Rey (2000) supports these results strongly: a "gravity" specification explains very well the bilateral distribution of gross cross-border equity trade. In that paper, transaction costs are interpreted as information costs, which are increasing with distance.

\section{Perfect Competition on Asset Markets}

The monopolistic structure of the asset markets is a natural consequence of the imperfect substitutability of assets in our model. It is not key to most of our results, however. To see this, suppose that project owners, when selling shares of their projects on the stock market, do not exploit their monopolistic power. In this case, it is easy to show that in all expressions derived above, the term $(\sigma / \sigma-1)$ is replaced by 1 . This term measures the mark-up over marginal cost that project owners are able to impose when they exploit their monopolistic power. It therefore goes to 1 in the perfect competition case. Except for result 1 , all the following results are qualitatively unchanged. Result 1 no longer holds because in this case, agents will hold as much of their own project as of the projects of the other domestic agents. Hence, there will be full home diversification although the home bias will remain.

Graph 1 makes clear what happens when project owners are not able to impose any mark-up over their marginal cost. In the two countries, the price of assets will be lower than in the non-competitive setting but it will still be higher in the large country than in the small country as $p_{A}=\frac{\beta}{N} d^{1-1 / \sigma}\left[n_{A}+n_{B} \phi\right]^{1 / \sigma}$ and $p_{B}=\frac{\beta}{N} d^{1-1 / \sigma}\left[n_{B}+n_{A} \phi\right]^{1 / \sigma}$ in this case. This also implies that the number of risky projects per agent will be lower in the perfect competition case. Also, the diversification will be larger in both countries but still more important in the large country as $\alpha_{A}=\frac{n_{A}-1+n_{B} \phi}{n_{A}+n_{B} \phi}$ and $\alpha_{B}=\frac{n_{B}-1+n_{A} \phi}{n_{B}+n_{A} \phi}$ in this case. 


\section{Welfare Implications}

The market equilibrium is not efficient for two reasons. First, a world planner would choose a higher number of projects per person than in the market equilibrium. This is because an agent, when developing a new project, does not internalise the benefits that other agents get from the risk-diversification provided ${ }^{20}$. The other source of inefficiency in the model is the imperfectly competitive structure of the asset market which leads agents to choose to retain too much ownership of the projects they have developed themselves so that in equilibrium there is too little diversification.

To compare the market and the planner's equilibrium we choose the symmetric case where both countries are identical $\left(\mathrm{n}_{\mathrm{A}}=\mathrm{n}_{\mathrm{B}}\right)$ so as to ignore any distribution problem. The planner maximises the utility of a representative agent in A under the following resource constraint: $y=c_{1 A}+f\left(z_{A}\right)$. The planner's solution is the following:

$$
s_{A}^{A}=\frac{1}{n_{A}(1+\phi)} ; s_{A}^{B}=\frac{1-\tau}{1+\tau} \frac{\phi}{n_{A}(1+\phi)} ; f^{\prime}\left(z_{A}\right)=\frac{\beta}{N} d^{1-1 / \sigma} \frac{\sigma}{\sigma-1}\left[n_{A}(1+\phi)\right]^{1 / \sigma}
$$

which we can compare to the market equilibrium in the case of identical countries:

$$
\begin{aligned}
& s_{A}^{A}=\frac{1}{n_{A}(1+\phi)-1+\left(\frac{\sigma}{\sigma-1}\right)^{\sigma}} ; s_{A}^{B}=\frac{1-\tau}{1+\tau} \frac{\phi}{n_{A}(1+\phi)-1+\left(\frac{\sigma}{\sigma-1}\right)^{\sigma}} ; \\
& f^{\prime}\left(z_{A}\right)=\frac{\beta}{N} d^{1-1 / \sigma}\left[n_{A}(1+\phi)-1+\left(\frac{\sigma}{\sigma-1}\right)^{\sigma}\right]^{1 / \sigma}
\end{aligned}
$$

Result 7: The extent of diversification is too small in the market equilibrium: $s_{A}^{A}$ and $s_{A}^{B}$ are smaller than in the market equilibrium. The number of projects per agent is also smaller in the market equilibrium than in the planner's solution as long as the cost function is convex.

At first glance, comparing $\mathrm{z}_{\mathrm{A}}$ in (17) and in (18), it is not obvious that the former is larger than the latter. This is because there are two market failures that have contradictory effects on the choice of $\mathrm{z}_{\mathrm{A}}$ in the market equilibrium. On the one hand the externality already described means that there will be too few projects developed. On the other hand, in the market equilibrium, because the asset market is not perfectly competitive, the price of an asset is above its marginal cost. This induces agents to develop more projects. However, it can be shown that this second effect is always less important than the externality effect so that in equilibrium too few projects are developed, and too few assets traded.

It is also easy to show that to attain the social optimum in the market equilibrium, a single subsidy on the demand for traded assets is sufficient. This subsidy must be financed by a lump sum tax in the first period. It increases demand for assets and therefore diversification and also the price level so that in equilibrium the optimal number of assets is developed. The value of this subsidy is simply $s=1 / \sigma$, the degree of risk aversion. This makes sense as the more risk-averse agents are, the greater the monopolistic power of asset issuers and the more the welfare cost of the insufficient number of assets and market incompleteness.

20 Pagano (1993) and Acemoglu and Zillibotti (1997) analyse in a somewhat different context a similar pecuniary externality. 


\section{Domestic Transaction Costs and Issuing Costs}

To simplify the exposition, we have not introduced domestic transaction costs on asset markets in the main analysis. However, suppose that when agents buy domestic assets and receive the dividend on those assets, they have to bear transaction costs that resemble the international transaction costs we have analysed in the previous sections but which are lower than the international ones. We denote transaction costs of that sort $\tau_{\mathrm{A}}$ and $\tau_{\mathrm{B}}$ respectively on the asset markets of country A and B. We also allow for issuing costs: when firms issue shares, they incur costs even before the transaction stage. These issuing costs could be represented, at least partly, as proportional to the amount of shares issued: we suppose that these issuing costs are $\mathrm{u}_{\mathrm{A}}$ and $\mathrm{u}_{\mathrm{B}}$ per share issued and again incurred in units of the share itself.

The analysis is very similar to the analysis of international transaction costs and therefore we will not repeat all the steps for finding the equilibrium. The first order conditions of agents in the two countries give the demands for assets. The different demands for the assets are given by:

$$
\begin{aligned}
& s_{A}^{A}=\left(1-\alpha_{A}\right)\left(\frac{\sigma-1}{\sigma}\right)^{\sigma} \frac{\left(1-\tau_{A}\right)^{\sigma-1}}{\left(1+\tau_{A}\right)^{\sigma}}\left(1-\mathrm{u}_{\mathrm{A}}\right)^{\sigma} ; s_{B}^{B}=\left(1-\alpha_{B}\right)\left(\frac{\sigma-1}{\sigma}\right)^{\sigma} \frac{\left(1-\tau_{B}\right)^{\sigma-1}}{\left(1+\tau_{B}\right)^{\sigma}}\left(1-\mathrm{u}_{\mathrm{A}}\right)^{\sigma} \\
& s_{A}^{B}=\left(1-\alpha_{A}\right)\left(\frac{\sigma-1}{\sigma}\right)^{\sigma} \frac{(1-\tau)^{\sigma-1}}{(1+\tau)^{\sigma}}\left(\frac{p_{A}}{p_{B}}\right)^{\sigma}\left(1-u_{A}\right)^{\sigma} ; \\
& s_{B}^{A}=\left(1-\alpha_{B}\right)\left(\frac{\sigma-1}{\sigma}\right)^{\sigma} \frac{(1-\tau)^{\sigma-1}}{(1+\tau)^{\sigma}}\left(1-u_{B}\right)^{\sigma}\left(\frac{p_{B}}{p_{A}}\right)^{\sigma}
\end{aligned}
$$

The no diversification result (result 1) becomes stronger when domestic transaction costs and issuing costs are taken into account.

The portions of each project sold on the stock market are now:

$$
\begin{gathered}
\alpha_{A}=\frac{\left(n_{A}-1\right) \phi_{A}+n_{B} \phi}{\left(n_{A}-1\right) \phi_{A}+n_{B} \phi+\left(1-u_{A}\right)^{1-\sigma}\left(\frac{\sigma}{\sigma-1}\right)^{\sigma}} \\
\alpha_{B}=\frac{\left(n_{B}-1\right) \phi_{B}+n_{A} \phi}{\left(n_{B}-1\right) \phi_{B}+n_{A} \phi+\left(1-u_{B}\right)^{1-\sigma}\left(\frac{\sigma}{\sigma-1}\right)^{\sigma}}
\end{gathered}
$$

where $\phi_{i}=\left(\frac{1-\tau_{i}}{1+\tau_{i}}\right)^{\sigma-1} ; i=A, B$ and is less than 1 , and decreasing in transaction costs. The prices of assets in the two countries are: 


$$
\begin{aligned}
& p_{A}=\frac{\beta}{N} d^{1-1 / \sigma}\left(1-u_{A}\right)^{-1 / \sigma}\left[\left(n_{A}-1\right) \phi_{A}+n_{B} \phi+\left(1-u_{A}\right)^{1-\sigma}\left(\frac{\sigma}{\sigma-1}\right)^{\sigma}\right]^{1 / \sigma} \\
& p_{B}=\frac{\beta}{N} d^{1-1 / \sigma}\left(1-u_{B}\right)^{-1 / \sigma}\left[\left(n_{B}-1\right) \phi_{B}+n_{A} \phi+\left(1-u_{B}\right)^{1-\sigma}\left(\frac{\sigma}{\sigma-1}\right)^{\sigma}\right]^{1 / \sigma}
\end{aligned}
$$

The impact of the financial market equilibrium on the choice of the number of risky projects is given by the modified condition on the optimum number of projects per agent:

$$
f^{\prime}\left(z_{A}\right)=p_{A}\left(1-u_{A}\right) ; f^{\prime}\left(z_{B}\right)=p_{B}\left(1-u_{B}\right)
$$

Result 9: Markets with high domestic transaction costs and issuing costs will be less developed ( $\alpha$ will be smaller). Asset prices will be lower on markets with high domestic transaction costs and higher on markets with high issuing costs. Both high transaction costs and issuing costs induce agents to develop less risky projects.

Proof: comparative statics on equations (20), (21) and (22)

The intuition can again be understood in reference to a graph with the demand and supply of assets (see Graph 2 below). Higher domestic transaction costs reduce the domestic demand for assets which shifts the demand curve downwards. The supply curve is in this case unaffected. In the case of issuing costs, the marginal cost of issuing a share is increased by $1 /\left(1-\mathrm{u}_{\mathrm{A}}\right)$ and $1 /\left(1-\mathrm{u}_{\mathrm{B}}\right)$ respectively which shifts the supply curve to the left. The demand curve, not inclusive of issuing costs is unaffected. On Graph 2, we illustrate the impact of transaction costs and issuing costs on asset prices and on the diversification choice, i.e. the supply of assets (here not inclusive of the issuing costs paid in shares).

\section{Graph 2: The impact of domestic transaction costs and of issuing costs}

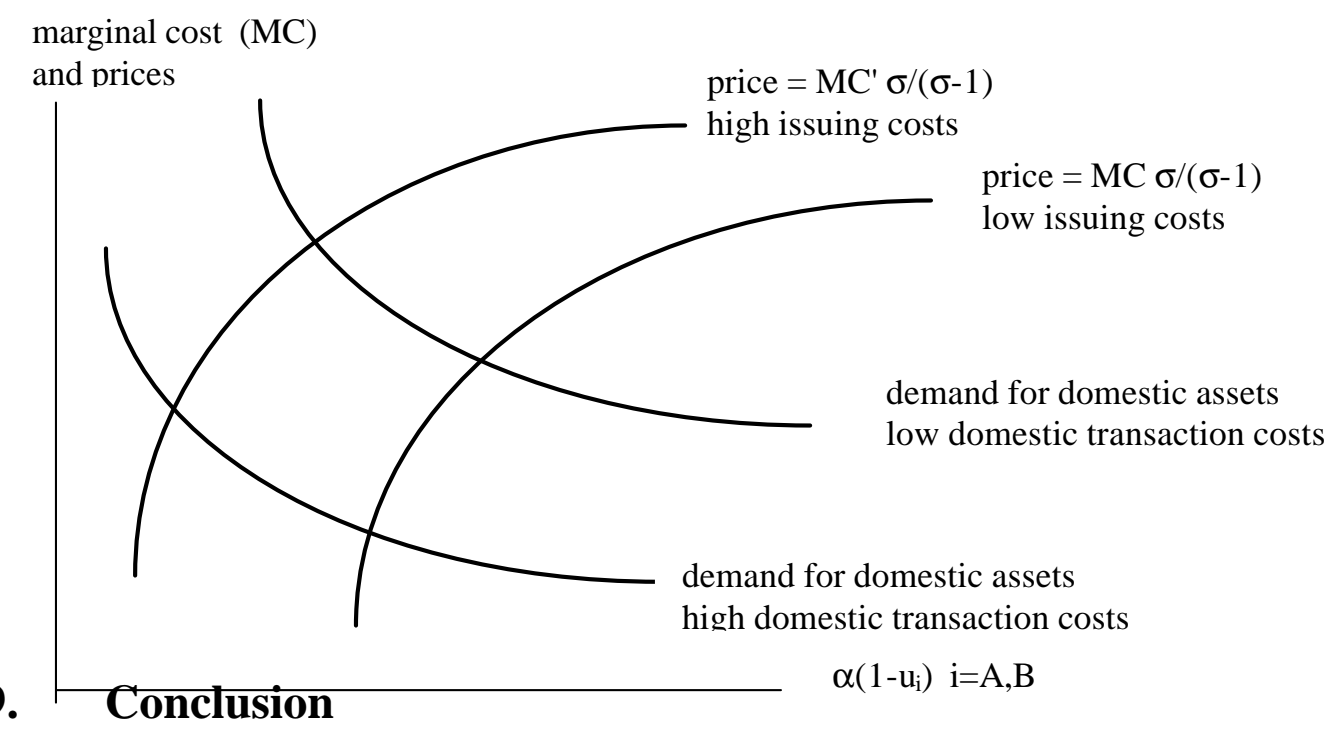

The paper has presented a two-country macroeconomic model where the size of the economies (or financial areas) matters for the determination of asset returns, the breadth of financial markets, and the pattern of trade in risky assets. These issues have been largely overlooked by the traditional macroeconomic and finance literature. They arise very naturally in our model 
because we have heterogeneous agents, incomplete asset markets and transaction costs. The model is very simple and conveys clear intuitions. If world financial markets are segmented, then large areas will have more developed financial markets than small areas, ceteris paribus. This is because transaction costs induce a home bias and the demand for the assets of the large areas are higher. This higher demand leads to a higher price of capital in equilibrium. This in turn induces agents to develop more projects, sell a bigger share of their assets and enables better risk diversification. Our modelling approach finds support in existing empirical evidence on share prices in segmented markets: the share price of companies listing in large stock markets tends to rise significantly. It also finds strong support in recent empirical evidence on the pattern of bilateral cross-border gross flows in equity.

In Martin and Rey (2000), we apply the theoretical framework developed here to analyse the impact of regional financial integration on welfare. We show that when transaction costs between two markets fall, welfare increases inside the newly-created bloc. The effect on an outside country is ambiguous: on the one hand there is a positive impact because the increase in the number of assets enables all agents to better diversify risk. On the other hand, the financial terms of trade of agents who do not belong to the bloc deteriorate because the price of foreign assets increases. This suggests possible conflicts between currency blocs. It also points to possible strategic interactions. If an increase in international transaction costs has a positive financial terms of trade effect for the large country, this country may in certain circumstances prefer to have high transaction costs. Another possible extension of our basic framework would be to introduce non-traded goods. So far the theoretical literature has failed to provide a clear link between non-tradability in goods and asset holdings. This model could allow us to make progress on that front. Marrying monopolistic competition on the asset markets and the goods markets could also bring interesting results. But we leave these considerations for future research. 


\section{References}

Acemoglu, D. and Zilibotti, F. (1997), 'Was Promotheus Unbound by Chance? Risk, Diversification and Growth', Journal of Political Economy, Vol. 105, pp.709-751.

Alexander, G., Cheol, E. and Janakiraman, S. (1988), 'International Listings and Stock

Returns: Some Empirical Evidence', Journal of Financial and Quantitative Analysis, Vol. 23, pp.135-151.

Allen, F. and Gale, D. (1994), 'Financial Innovation and Risk Sharing', MIT Press.

Amihud, Y. and Mendelson, H. (1986), 'Asset Pricing and the Bid Ask Spread', Journal of Financial Economics, Vol. 17, pp.223-249.

Bekaert, G. and Harvey, C. (1997), 'Foreign Speculators and Emerging Equity Markets', NBER WP 6312, December.

Bisin, A. (1998), 'General Equilibrium with Endogenously Incomplete Financial Markets', Journal of Economic Theory, Vol.82, No. 1, pp.19-45.

Cole, H. (1993), 'The Macroeconomic Effects of World Trade in Financial Assets', Federal Reserve Bank of Minneapolis Quarterly Review, Vol. 17, No. 3.

Dixit, A. and Norman,V. (1980), Theory of International Trade, Cambridge University Press.

Foerster, S. and Karolyi, A. (1998), 'The Effects of Market Segmentation and Investor Recognition on Asset Prices: Evidence from Foreign Stocks Listing in the US', Journal of Finance, forthcoming.

Hardouvelis, G., Malliaropulos, D. and Priestley, R. (1999), 'EMU and European Stock Market Integration', CEPR DP 2124, April.

Helpman, E. and Razin, A. (1978), A Theory of International Trade under Uncertainty, Academic Press: New York.

Krugman, P. (1979), 'Increasing Returns, Monopolistic Competition and International Trade', Journal of International Economics.

Magill, M. and Quinzii, M. (1996), Theory of Incomplete Markets, MIT Press: Cambridge.

Martin, P. and Rey, H. (2000) 'Financial Integration and Asset Returns', Discussion Paper No. 451, Centre for Economic Performance, London School of Economics.

Merton R. (1987), 'Presidential Address: A Simple Model of Capital Market Equilibrium with Incomplete Information', Journal of Finance, Vol. 42, pp.483-510.

Miller, D. (1999), 'The Market Reaction to International Cross-Listings: Evidence from Depositary Receipts', Journal of Financial Economics, Vol. 51, pp.103-123. 
Obstfeld, M. and Rogoff, K. (1996), 'Foundations of International Macroeconomics', MIT Press.

Pagano, M. (1988), 'Trading Volume and Asset Liquidity', Quarterly Journal of Economics, pp.255-274.

Pagano, M. (1989), 'Endogenous Market Thinness and Stock Price Volatility', Review of Economic Studies, Vol. 56, pp.269-288.

Pagano, M. (1993), 'The Flotation of Companies on the Stock Market: a Coordination Failure Model', European Economic Review, Special Issue on Finance, Vol. 37, No. 5, pp.1101-1125

Persson, T. and Svensson, L. (1989), 'Exchange Rate Variability and Asset Trade', Journal of Monetary Economics, Vol. 23, pp.485-509.

Portes, R. and Rey, H. (2000) 'The Determinants of Cross-Border Equity Flows', Discussion Paper No.446, Centre for Economic Performance, London School of Economics.

Stulz, R. (1999a), 'Globalization of Equity Markets and the Cost of Capital', paper prepared for the SBF/NYSE Conference on Global Equity Markets.

Stulz, R. (1999b) 'International Portfolio Flows and Security Markets', mimeo, Ohio State University.

Svensson, L. (1988), 'Trade in Risky Assets', American Economic Review, Vol. 8, pp.375-394. 